\title{
Flood Inundation Warning and Relief System Based on GIS and Remote Sensing
}

\author{
B. Teena ${ }^{1}$ and Dhruva R. Rinku ${ }^{2}$ \\ ${ }^{1}$ PG Scholar, CVR College of Engineering/ECE Department, Hyderabad, India \\ Email: teenapaul23@gmail.com \\ ${ }^{2}$ Assoc. Professor, CVR College of Engineering/ECE Department, Hyderabad, India \\ Email: rinkudhruva.ravi@gmail.com
}

\begin{abstract}
Due to climate change and uncontrolled urbanization, frequencies of floods are increasing these years. In a developing country like India, flood creates a great havoc which takes many years to get restored. To mitigate the affect of flood disaster, an accurate flood inundation warning is required.

In this system, a geographic information system (GIS) model is developed on the basis of Digital Elevation Model (DEM) and the shapefile of buildings. They accurately analyze the land behavior in presence of flood and identify the flood inundation risk of different places. This would be helpful to take active measures to mitigate the destruction caused by flood, in time being. Global Precipitation Measurement's (GPM) half-hourly rain data is used to find the impact of rain on current flood conditions in various areas; this helps to warn the people living in nearby places, as they also may have threat of life and property.

This system also contains the flood relief system which is a web-based system (developed using PHP) having web application and MySQL database, to create a platform that provides a foundation that prepares the donors to help the victims of flood with various kinds of donations. This system informs the donors by sending an SMS using a GSM module. This is done to prepare the donors with their donations, immediately after the flood warning is released. These donations would equip the authorities to provide essential needs of the flood victims. This system is developed for Mumbai city, India's largest city as it is a city affected by flood almost every year causing great destruction of property and life.
\end{abstract}

Index Terms: GIS, remote sensing, DEM, Ardunio, MySQL, PHP, GSM

\section{INTRODUCTION}

Temporary overflow of water to a normally dry area due to entrance of large amount of water which cannot be drained at the same rate and gets accumulated is called flood. The source of this large amount of water can be heavy rainfall, precipitation, rise in water level of river, broken dams which may be caused due to levees failure, improper drainage basins, natural disasters like storm surges and earthquake in water, known as Tsunami. Whatever may be the source of flood water but it has the potential to destroy the life and property in huge amounts, that too without warnings or signs which makes people, authorities and government powerless and helpless to avoid the havoc it creates.

Flood is the deadliest natural disaster which affects millions of people every year. Various technologies are being developed to warn people for flood and mitigate the damage, yet many millions of people are affected by flood. International disaster database declares that in 2018, 109 floods occurred throughout the world which devastated the lives of many people as shown in "Figure 1" [1]. India is a developing country which is affected by flood every year especially in its monsoon season which is from June to September. The southern and north-western India receives $50 \%-75 \%$ of their total annual precipitation in this season. India receives average rainfall of 200-300 $\mathrm{mm}$ [2].

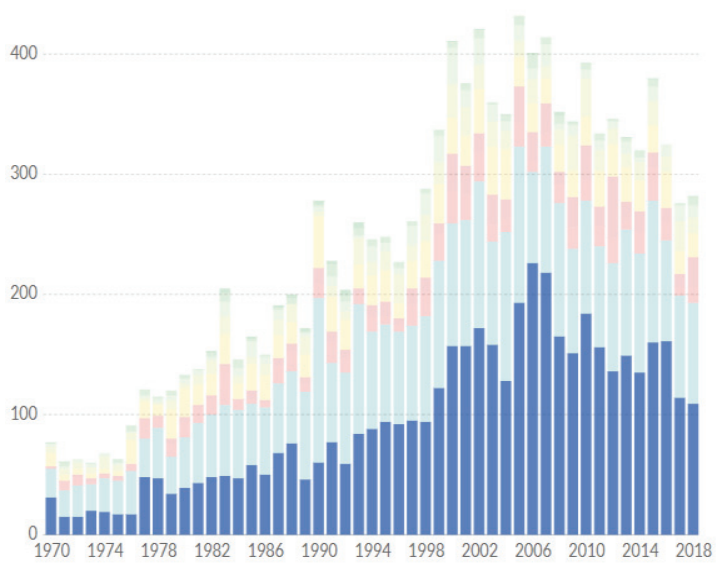

Figure 1. Statistics of floods occurred in 1970-2018.

Mumbai is taken as study area for this work because Mumbai is the largest city on India's Konkan coast in west coast and it is the financial capital of India. Mumbai is the most densely populated metropolitan city of India with population of $18,394,912$ as of 2011 . Mumbai generates $6.160 \%$ of India's GDP, accounts for $25.0 \%$ of industrial output from India and brings $70.0 \%$ of capital transactions to India's economy. The ports of Mumbai execute $70.0 \%$ of India's maritime trade. This city provides a lot of employment opportunities, for instance, the factories in Mumbai produces $10.0 \%$ of total factory employments in India. The industries in Mumbai produce $25.0 \%$ of total industrial outputs for India. Mumbai benefits the Indian government's revenue as the citizens of Mumbai pay 33.0\% of total income tax collections, $60.0 \%$ of total customs duty collections, and $20.0 \%$ of total central excise tax collections in India. The companies of Mumbai play a vital role in foreign trade as $40.0 \%$ of India's foreign trade is done in Mumbai [3]. These factors get disturbed when Mumbai is hit by floods every monsoon and produce a very negative impact on the economy of its state and that of the nation. 
In monsoon season western and central India receives more than $90 \%$ of their total annual precipitation. India has coastline of $7516.6 \mathrm{~km}$ which cross through Mumbai, this makes it more prone to flood due to water overflow from coastal seas. Apart from this uncontrolled construction, antiquated drainage system and ruination of Mangrove ecosystems due to aquaculture expansion increase the damage cause by floods in Mumbai [4].

In 2017 Mumbai was flooded due to $468 \mathrm{~mm}$ of rainfall within 24 hours and two to three days of heavy rainfall over central India; this killed 14 people. This flooding caused a building to collapse, killing at least 21 people [5]. The transport system of trains and roadways was collapsed.

In 2005 Maharashtra floods, which were caused due to $944 \mathrm{~mm}$ (37.17 inches) of rainfall within 24 hours, $644 \mathrm{~mm}$ (25.35 inches) within 12 hours which killed 1,094 people [6] The loss incurred was about Rs. 550 crores (US\$100 million). The damage caused to transport was very huge.

In these ways Mumbai floods are bringing a huge damage of life and property. So, it is very crucial for the nation to preserve its financial capital Mumbai from frequent flood damage [7]. In this work, a GIS based model is developed which identifies the blue-spots (place where the water gets in and accumulates because it has no outpour) which makes the buildings of this area more prone to flood, those buildings are identified using ArcGIS [8], a GIS based software.

The amount of rain water, which totally inundates an area that is prone to flood, is calculated and is known as the fillup value; later this value helps to identify when the flood water will flow out to its nearby places. The near-real time precipitation data generated through remote sensing is processed to identify the present condition of flood through which a flood warning can be released for the people living nearby. A flood relief system is developed which contains a website based on PHP, this enables the donors to get registered and it stores their information in a database. These donors are informed about the potential flood victims who may suffer, when the flood warning is generated so that they can send their donations to the flood victims.

\section{LITERATURE SURVEY}

There are many existing flood warning systems such as, Central Water Commission (CWC) of government of India. It monitors the flood situation by observing discharges along the major rivers in the country and issues a flood warning. This Flood warning Network has 325 stations which covers 197 low lying cities and towns. This system is able to mitigate low to moderate level of floods, but it fails to be accurate in case of Mumbai which have only four rivers and which is mainly hit by pluvial flood almost every year.

Dadasaheb K. Mane [9] proposed a flood warning system which uses ultrasonic sensor, deployed by the river side to monitor the water level of the river, this system monitors flood but any disturbance caused due to wind or sound of water alters the data. Moreover, the ultrasonic sensor has lesser range, which is up to 3 meters. Hence, it is not much reliable. Barometric Pressure sensor is implemented to identify the water level of the river as it avoids all the disturbances using a pipe and generates an alert, as proposed by Azid et al. [10]. But it is limited only for fluvial flood where flood occurs mainly due to river overflow and it views the incoming flood only from one region i.e. where the sensor is deployed in case of a large river, multiple sensors can help to understand all the flood sources. Moreover, this can warn only the people residing by river side, which is not the exact case of Mumbai.

According to Khalaf et al. [11] and Devaraj et al. [12], water level sensor can be used to sense the water level in rivers; forming a network of these sensors can produce a flood warning but fails to give information of the direction in which flood water is flowing, especially in a residential area. The information about the direction of flow of flood water would help much more accurately. Hence it produces a flood warning but not accurate enough to help people of Mumbai due to inadequate sensors in the network which would tell the direction of flow of flood water. Moreover, the rain data must also be considered to track the current flood condition.

Dense number of rain gauges that form a network can help to track the precipitation rate and identify flood risk as proposed by Carbone et al. [13], but it is not economically feasible for India, moreover it should be setup in a flat area, a place which has no blockage towards sky and must be away from any kind of blockages such as buildings, trees, etc. Moreover, this network requires maintenance of the rain gauges, as damage of a single rain gauge can diminish the accuracy. This is hard to implement in Mumbai city which has very dense population that makes this approach inappropriate.

To get accurate precipitation data for flood warning in addition to number of rain gauges, optimal locations to setup rain gauge is also vital, Kriging technique is used for this purpose, according to Sajal Kumar Adhikary et al. [14], this technique provides good quality rainfall estimates to release accurate flood warning, but it takes a lot of effort to practically implement it, satellite data can be used as a substitute to get rainfall information in flood-plain. In addition to this the study of terrain's surface and hydrology helps better to build an accurate flood warning system as it tells where the flood water is going to get accumulated and where inundation will occur.

Flood-plain mapping helps to understand the direction of flow of flood water, which can be implemented by DEM. It is the raster data set which provides the information of elevation at every location. This is used to compute the structural properties of watershed area to plot the susceptibility to floods according to Keighobad et al. [15]. This data provides the information of flood risk in an area, but it is a static topographic model, a dynamic model helps better.

In this work, DEM map of Mumbai is used to identify the areas of sinks. All the sinks belonging to the same group are identified and grouped together. The buildings which fall under the sink regions are identified and declared as the region having risk of floods. Moreover, remotely sensed precipitation data is processed to release flood warning. The objective of this work is to develop a customized flood warning for Mumbai, improve the accuracy of flood 
warning using sinks, release timely warnings and develop a flood relief system.

\section{FLOOD WARNING SYSTEM BASED ON SINKS}

\section{A. Identification of flood-risked Buildings}

To understand the affect of flood in different areas, the elevation data of the affected area is to be studied. A Digital Elevation model (DEM) map provides the elevation data of earth's surface. The DEM data of Mumbai used for this work is taken from NASA's STRM DEM data. This DEM data has to get geo-processed, in order to understand the flood dynamics.

GIS is a framework used for gathering, managing, and analyzing geological data. It integrates many types of data and performs various operations on them. The output of processed information is shown in the maps; they have specific geographical coordinates in reference to the actual geographical coordinates. The basic unit of a map is pixel or cell. ArcGIS is the software that provides a platform to perform geo-processing on the input data.

For this work DEM map is taken as input of the flood warning system. It has 90 meters horizontal resolution. It also has a vertical resolution or accuracy. The elevation shown in DEM map, which is less than vertical accuracy, might be an error. These errors should be removed before geo-processing the data to obtain flood warning. The DEM map is made error free and is used to identify sinks in the flood plain area that is shown in DEM map. All the cells having elevation less than zero are identified as sink cells, where as zero is considered as the normal ground elevation.

All the pixels having sinks and the pixels which have continuous sinks are grouped to find out the whole region of sink. These regions are dissolved to identify the sinks as whole which gives us the information about the inundation areas as the flood water gets accumulated in these regions.

Vector map is a map consisting of points, lines or polygons used to represent a delineation of threedimensional data, such as parks, buildings or water bodies. The collection of vector data is called a shape-file as shown in "Figure 2". A shape-file contains a table attached to it, called as attribute table which stores the data of the vectors drawn in the shape-file. A shape-file is required to draw the delineation of the shape of raster (a 3-D object).

In order to have more accuracy of flood warning i.e. up to building's level, the shape-file of buildings is superimposed on the sink's map. To exactly super-impose a map on other map, it must be geo-referenced in order to get the information without any errors of direction. To match a digital map to real world 'geo-referencing' is done. Georeferencing is the assignment of a real world geographical coordinate system to a digital map, which specifies each location as a set of latitude (horizontal) and longitude (vertical).

Latitude is a point formed by the angle between the plane of equator and the centre of the Earth. Longitude is the angle formed by a reference meridian to another meridian, from east to west. Geo-referencing is done to precisely match different layers over a base layer on a map, in this case the geo-referencing is used to map the buildings over sinks map, and this is done to get building level accuracy. Geoprocessing is done to identify the buildings which have the risk of flood, and to warn them.

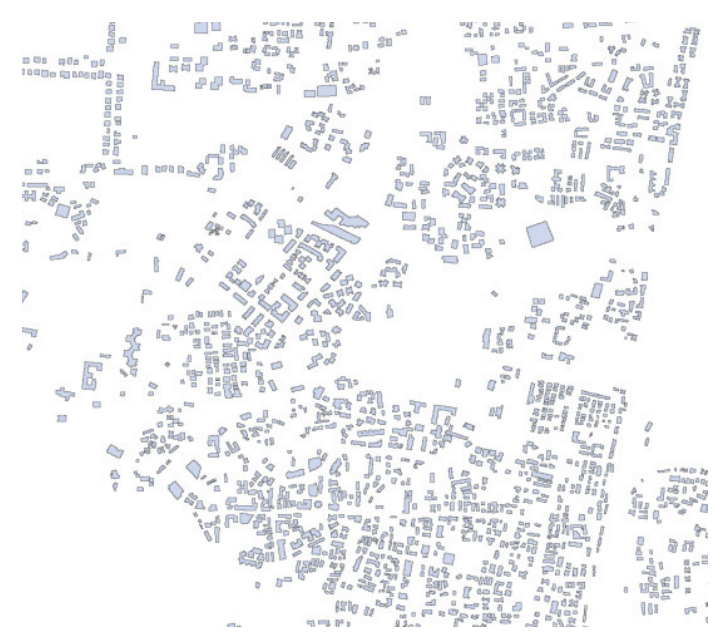

Figure 2. The Mumbai city buildings Shape file.

The flood risked buildings are pin-pointed by implementing the algorithm shown in the flow chart of "Figure 3". This is implemented by creating the model in ArcGIS and automating the model by a python script which takes in the inputs, automatically processes it and provides the flood risked buildings as output.

This provides us with a static model of area having sinks, where the flood water gets accumulated. To get more accurate flood warning system, we have to make the flood warning dynamic, for that the hydrological aspects of this area must be considered, such as flow direction of water.

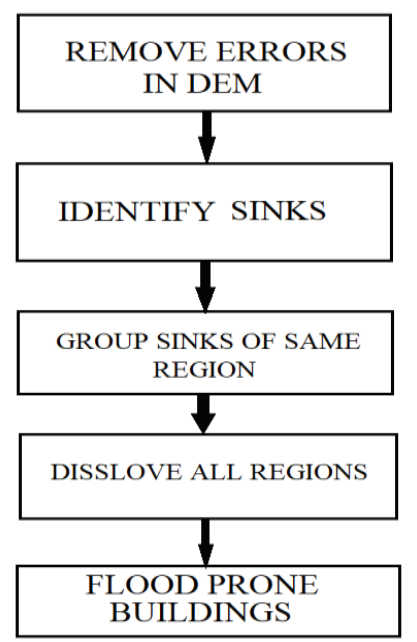

Figure 3. Flood-risked buildings Identification Flow chart.

\section{B. Identification of fill-up value of sinks}

To identify situation when the accumulated flood water will flow out to its neighboring places, the fill-up value is to be identified. For this purpose the volume of sinks can be identified by adding the elevation of all pixels; this addition will provide the height. The area of sinks is identified by 
finding the area of pixels of different regions of sinks. The inundation in an area can be caused by two reasons; first reason is due to precipitation and another is due to water flowing from higher elevation to lower elevation area. To identify the water accumulated in an area besides that which is due to precipitation, the flow direction must be considered. The flow direction of water is calculated by identifying the steepest continuous neighbor pixel for a given pixel, from the eight surrounding pixels, this provides the flow direction map.

Inundation mainly occurs in the area where the water flows in but does not flow out (which means the region formed by combination of continuous pixels where none of surrounding pixels is having steepest elevation, from which the water can flow through), this region is called a watershed. A watershed is an area on the top of the slope which has a common point for concentrated drainage flow known as pour point. Pour point is the lowest point in the boundary of watershed. A watershed may contain many watersheds which are called as sub-basins. The watershed area is described from the flow direction, which is derived from the DEM. Watershed area is used to determine the catchment area for precipitation data, as the affect of rain in any part of a region is same as that of whole region because the water doesn't flow out till it reaches the fill-up value. The fill-up value gives the information when the water will start flowing out of the watershed area and will make the nearby areas inundated and it is derived from "Eq. (1)".

$$
\text { Fill-up value }=\text { Sink volume } / \text { Watershed area }
$$

\section{Finding current situation of flood using Near-Real time precipitation data}

The volume of sink and the watershed area is used to determine the fill-up value of the sink. After determining the fill-up value the near real-time precipitation data is used to dynamically check whether the sink is filled or not, this is done by identifying whether the current rainfall has exceeded the height of pour-point of sink, which gives the information of inundation for that area. This information can be used to warn the people living in a watershed region and nearby places and helps the authority to evacuate the people residing there.

\section{Web-Based Flood relief system}

The flood relief provided by the government is not available soon and not sufficient. To meet this lack, a large group of donors are required to be prepared well before, who can send relief to the flood victim's for the time being and can help them. To prepare this system the donors are made to sign up for donations through a web-page, especially the donors residing in the nearest unaffected regions. So that when a flood warning is released, donors are sent an SMS which gives them the information of flood victims suffering in a particular place, and encourage them to come forward and send donations to help the flood victims. These donors are informed to get prepared well before for the donations and when need arises the victims can receive their help from them.
PHP is a server-based backend language used to develop dynamic web pages. It is used here to develop registration webpage. HTML is used to develop static web-pages and CSS language is used to style the web-page. All these languages are used to develop a website where donors can sign-up, they have to give their information and phone number. All their data is stored in a database. When a flood warning is released this list of donors is retrieved from the database and the information of flood victims is given to them through SMS sent to their respective phone numbers.

\section{F. SMS containing donation information}

GSM module is used to send SMS using its SIM 900A module, it basically contains a modem. It is controlled by Arduino Nano which contains Atmel ATmega328 microcontroller; it operates on $5 \mathrm{~V}$ and at the clock Speed of $16 \mathrm{MHz}$. AT commands are used to control the modem. There are various commands for different operations such as AT+CGDAT for establishing a connection, ATD for dialing up a connection or AT+CMGS for sending SMS to a receiver. Flow chart as shown in "Figure 4" shows the process to send SMS which would inform the donors about the flood victims and would encourage them to help these people.

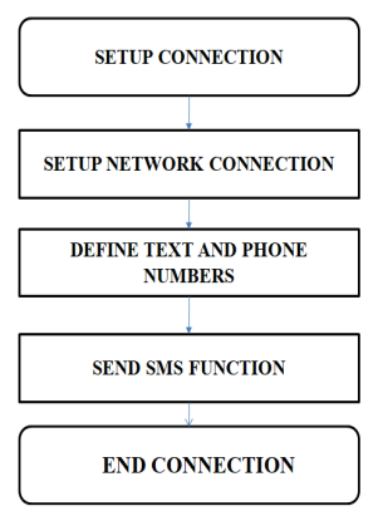

Figure 4. SMS over GSM communication Flow chart.

\section{IMPLEMENTATION \& RESULTS}

ArcGIS 10.5 is used to develop the sink based flood model. It is GIS based software which provides infrastructure to generate maps and manage geographic information. Shuttle Radar Topography Mission (SRTM) by NASA is used to get the remote sensed DEM data which determines the flow and displacement of the flood water over the land. It consists of 176 orbits, acquiring the Digital Elevation Model (DEM) of $80 \%$ of the land from between 60 degree North and 56 degree south latitude, except some areas where the hills block to measure the actual height. It has pixel size of 3 arc second (approx. 90 meters). It is arranged in the form of tiles of one degree each. This means each pixel of DEM map of Mumbai used in this work is of 90 meters as shown in "Figure 5".

In ArcGIS various geo-processing tools are used to develop this flood warning system such as, spatial analyst tool-set; it contains the tools required to process the data on 
the basis of its space. It is used to make the DEM map error free, identify the sinks, group the sinks and dissolve them to get overall sinks. Moreover, ArcGIS contains conversion toolset, which contains the tools used to convert the raster (3-D) data to vector data (2-D) for certain operations which operate only on a vector data. The output of first model has a map showing the risked buildings along with the table containing the data of regions having sinks with their depths. The model is scripted to get automated using the python plug-in called as arcpy.

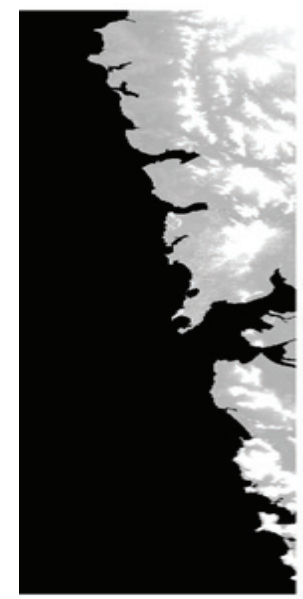

Figure 5. Mumbai DEM map.

The DEM map is made error free and the sinks are identified as shown in "Figure 6". The sink pixels give information about the inundated regions, all non-blue pixels show sink pixels of different depths, where the reddish pixels show the more depth sinks and light-colored pixels show less depth sinks.
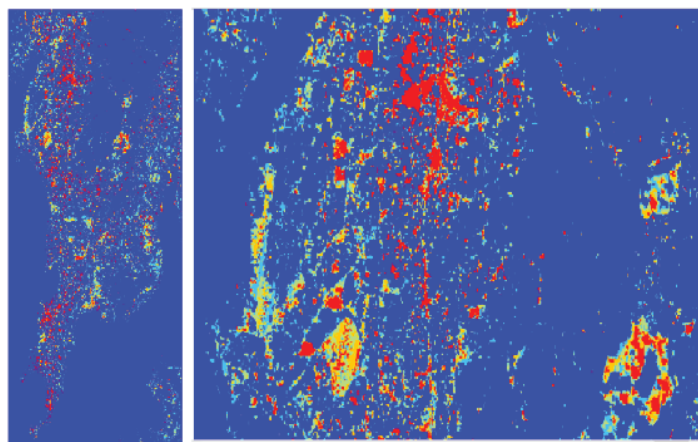

Figure 6. Sink pixels showing inundated regions.

The continuous sink pixels are grouped into a region as shown in "Figure 7". Different colors of groups distinguish the different depths of sink regions. The dark-colored ones reveal the deep sink regions whereas the light-colored reveal the less deep sink regions.
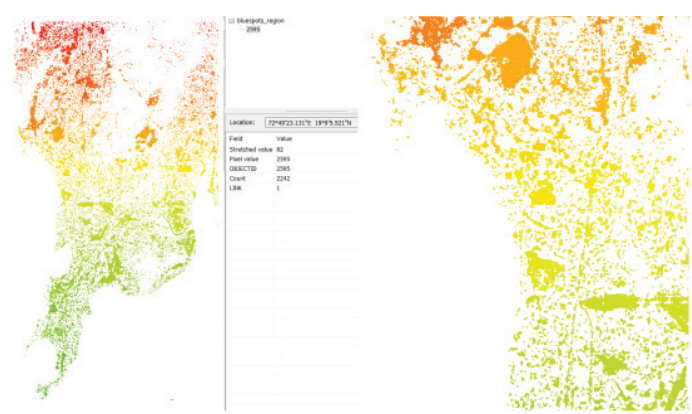

Figure 7. Grouped region's of sinks.

The grouped sinks are dissolved to identify the sinks in the entire Mumbai city. This will give us the information of the areas having inundation risks. The shape-file of buildings is mapped onto the map of dissolved sinks by georeferencing them, then the buildings having flood risk are identified. The pink colored region is the region of sink and the buildings within these sinks are having flood risk as they lie in sink region as shown in "Figure 8" the output also contains a table listing the buildings having flood risk.

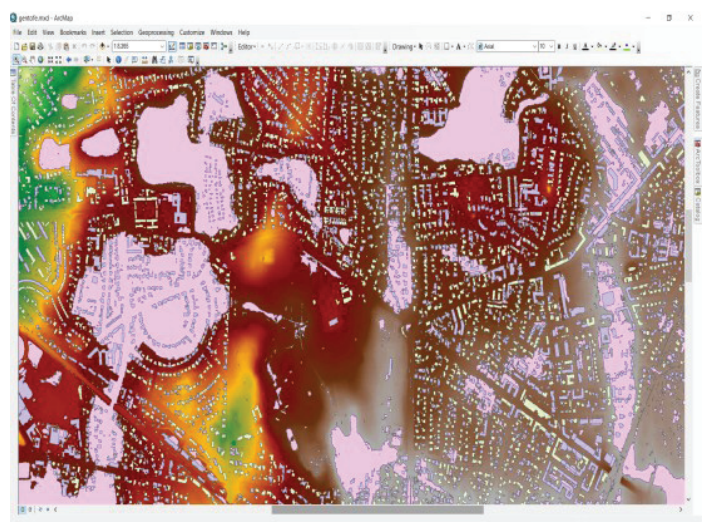

Figure 8. The buildings having flood risk are displayed.

The direction of flow of the flood water is determined by identifying the neighbor pixel having the least elevation, through which the water gets to flow, from the flow direction map the watershed area is derived as shown in "Figure 9". The different color regions display the different outpour points into different watershed areas.
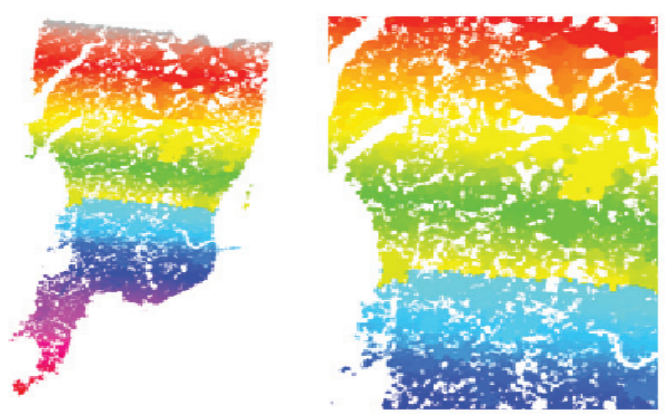

Figure 9. Various Watershed areas are displayed. 
The fill-up value is calculated using the sinks volume and the watershed area. The sink volume is identified by subtracting the average height of normal elevation from the elevation of sinks, this gives the height a sink when multiplied by the sink region's area it gives the volume of sinks. The volume of sinks and watershed area provides the fill-up value of sink as few of them are shown in the attribute table of "Table 1".

The fill-up value of all sinks in millimeters, so it is easy to analyze on the basis of rainfall data as rainfall data is also in millimeters. The OBJECTID and Value fields specify the unique number for each sink region. Count Field gives information about the number of features each individual region contains in it.

TABLE I.

TABLe Containing Fill-Up VALUes Of Every Watershed Region

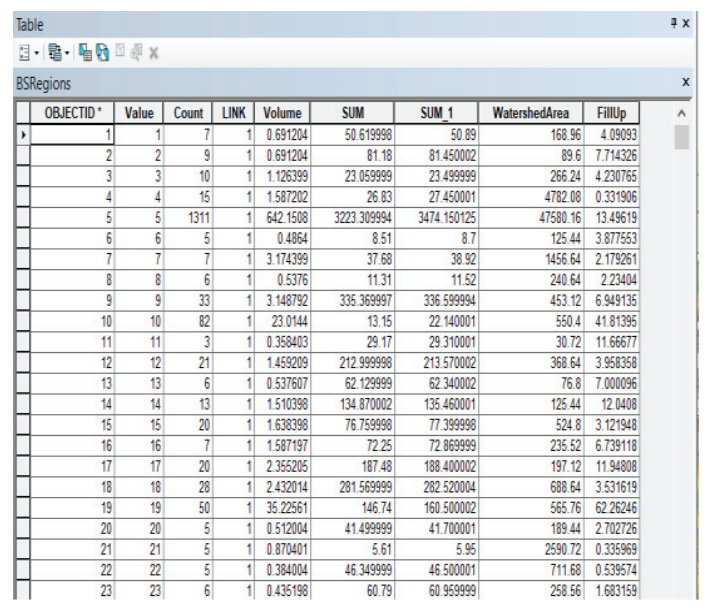

To make the flood warning system accurate, the NASA's GPM (Global Precipitation Mission) Integrated Multisatellite Retrievals for Global Precipitation Measurement mission (IMERG) rain data is taken. This provides near-real time half-hourly rain data of the Mumbai city. This data is analyzed with respect to the nearby rivers and the watersheds.

A model is developed in ArcGIS and scripted which continuously monitors the rain data with respect to land hydrology to analyze how rain is causing the flood such as its behavior on the rivers and the watersheds. Finally all the models are combined to produce the accurate flood warning in form of a table containing the names of buildings which face the risk of being inundated and need to get evacuated.

This model was implemented on $2^{\text {nd }}$ July 2019, when Mumbai received highest rainfall of that in last 10 years. The half-hour GPM IMERG data was constantly collected and implemented in the model of flood risked buildings and that of fill-up value which gave the result of buildings which were going to get inundated and needed to get evacuated.

The result gave a huge list of buildings where were having flood risk and needed to get warned to be in their homes and the old houses were to get evacuated. Some of the buildings for which warning is given are shown in the table given in "Table 2",
TABLE II

TABLE CONTAINING LIST OF FLOOD RISKED BUILDINGS.

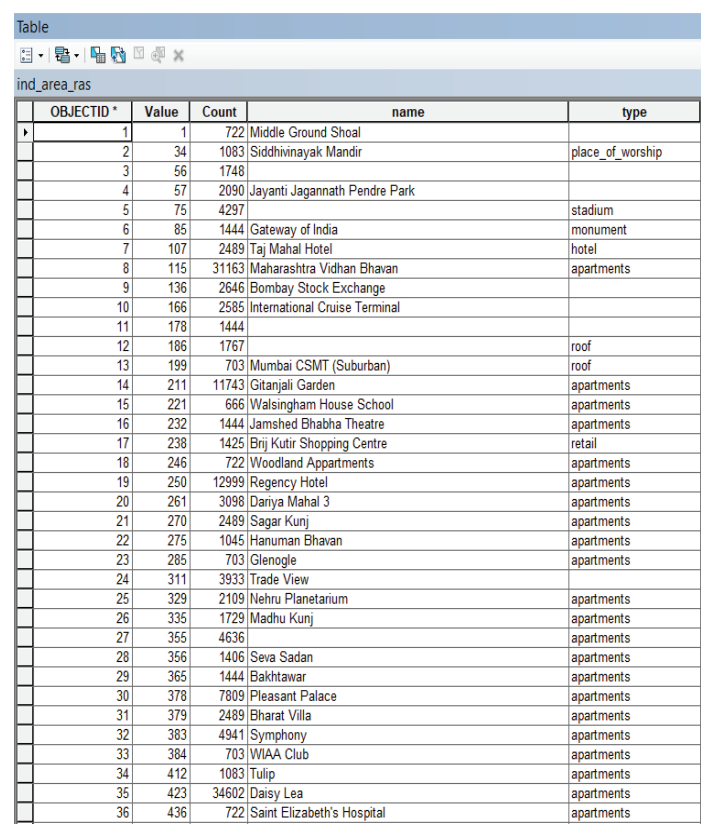

The website is created which displays the information of flood warning; it also contains the web-page where the donors can register themselves. To identify the website a domain name required and a server is needed to host the website. The web-page is created using PHP, which is connected to the phpMyAdmin database in backend, to store the donor's information as shown in "Figure 10". In order to send SMS to inform the donors about the flood victims and encourage them to come forward and help the flood victims by donating their donations, nearby donation centers were to be set up by non-government organizations. In this way this website acts as a mediator to connect the donors with the non-profit organizations and provides the facility to help the flood victims.

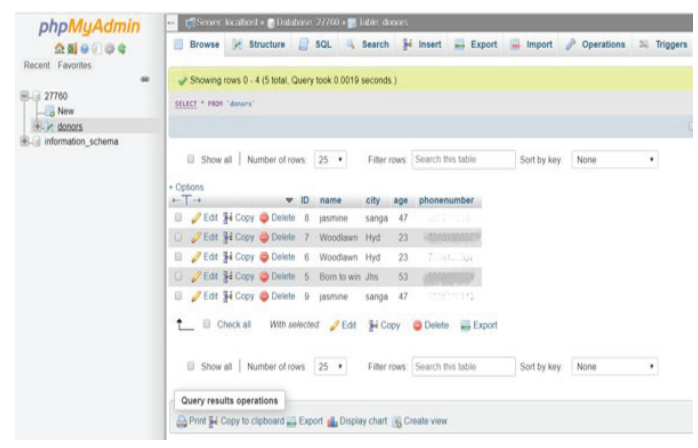

Figure 10. Donor's information is stored in the database.

When the flood warning is released the donors are send a personalized SMS asking them to help the flood victims by providing their donations to the victims. To automate this work as it is very time consuming manually, a device is created dedicated to send SMS by using Ardunio nano, which is used to send commands to the GSM module as shown in "Figure 11". 


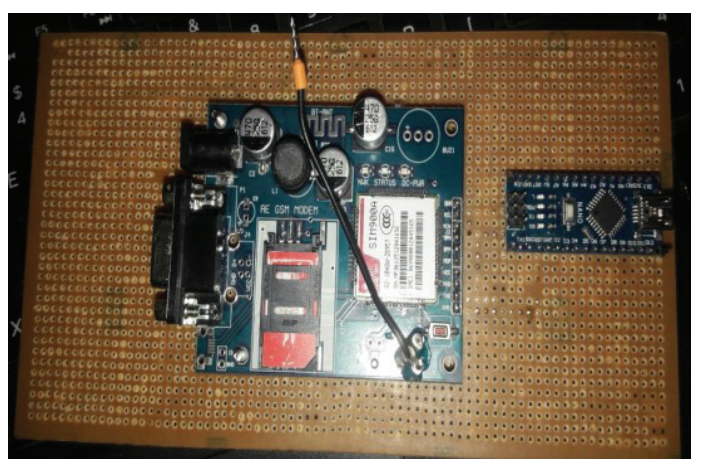

Figure 11. GSM based Device that sends SMS.

This flood warning system uses DEM of 90 meters accuracy to create a static model of sinks and identifies the buildings having inundation risk which is very accurate. It also takes GPM IMERG data having 0.1 arc seconds of accuracy i.e. 11 kilometers. This data helps to study the impact of rain on the Mumbai floods, the direction of flow of flood water, where the water gets accumulated and the pour points with respect to the falling rain. The models are automated using python script which takes very less time to execute as soon as the half-hourly averaged rainfall data is available as input.

The existing flood warning system by $\mathrm{CWC}$ releases flood warning, district wise [16] as it is accurate in providing the information regarding the districts only, but more accurate system helps the flood victims a lot more such as this work which produces flood warning as per buildings.

The existing rain gauge based flood warning system [17] has less accuracy than this work as it can produce flood warning up to street level, which is good but not much accurate. With rain gauge system the accuracy can be improved by deploying more number of rain gauges which is not much feasible. This work also overcomes the limitation of rain gauges as it takes the remote sensed rain data to monitor the formation of flood and produce a flood warning.

\section{CONCLuSions}

Flood is the most devastating natural disaster in India. The flood inundation warning system should be capable of accurately mapping the effect of flood over a region. The GIS model is produced, which identifies the sinks in different regions and maps it according to the buildings constructed in that area. This gives us the information about affected buildings. Their fill up value is calculated based on the sink volume and the watershed area. The buildings constructed within the sink area are pronounced as buildings having flood-risk as these areas have no outpour till the flood water will reach the level of their pour-point. These kinds of buildings are determined. With the help of near-real time rain data through remote sensing the outpour time of the inundated areas are calculated and the flood warning is released to the nearby places. Hence, an accurate flood inundation warning up to buildings level is released.
The flood relief system is developed based on the website which registers the concerned donors for the flood relief and this data is stored in the database. From here the GSM module, controlled by Arduino nano sends the donors the flood information through SMS, even before the flood inundation starts the authorities are equipped with donations which are necessary for the victims.

In future this system can be improved by using the précised rainfall prediction data with this model to get more accuracy also more accurate DEM data and remote sensed data from aircrafts or satellite with high accuracy can be used.

\section{REFERENCES}

[1] EMDAT (2019): OFDA/CRED International Disaster Database, Université catholique de Louvain - Brussels Belgium.

[2] T.N. Krishnamurti."Indian monsoon" Encyclopædia Britannica. Encyclopædia Britannica, inc. October 12, 2015.

[3] T Thomas."Mumbai a global financial centre? Of course!" Reddif. November 18, 2008

[4] Mangroves for coastal defence, 2014 Wetlands International and The Nature Conservancy.

[5] The Times of India."Mumbai rains: Misery all around, BMC says the situation is 'exceptional'". August 30, 2017.

[6] Millions Suffer in Indian Monsoon, BBC News, 1 August 2005.

[7] Rain Brings Mumbai to a Halt, Rescue Teams Deployed, The Hindu, 5 July 2006.

[8] ArcGIS for Developers."What is ArcGIS?".Esri https://developers.arcgis.com/labs/what-is-arcgis/

[9] Dadasaheb K. Mane (2013). Disaster Flood Alert System Using Ultrasonic Sensor. International Journal of Engineering Research \& Technology (IJERT). Vol. 2 Issue 1, January2013.

[10] Azid, S. \& Sharma, Bibhya \& Raghuwaiya, Krishna \& Chand, A. \& Prasad, S. \& Jacquier, A. (2015). SMS based flood monitoring and early warning system. ARPN Journal of Engineering and Applied Sciences. 10. 6387-6391.

[11] Khalaf, Mohamed. (2011). Flood Detection using Sensor Network and Notification via SMS and Public Network.

[12] E. Devaraj Sheshu, N. Manjunath, S. Karthik and U. Akash, "Implementation of Flood Warning System using IoT," 2018 Second International Conference on Green Computing and Internet of Things (ICGCIoT), Bangalore, India, 2018, pp. 445-448, doi: 10.1109/ICGCIoT.2018.8753019.

[13] Carbone, Marco \& Garofalo, Giuseppina \& Tomei, G. \& Piro, Patrizia. (2014). Storm Tracking based on Rain Gauges for Flooding Control in Urban Areas. Procedia Engineering. 70. 256-265. 10.1016/j.proeng.2014.02.029.

[14] Sajal Kumar Adhikary, Abdullah Gokhan Yilmaz and Nitin Muttil Hydrol. Process. 29, 2582-2599 (2015) Hydrological Processes published by John Wiley \& Sons Ltd. Optimal design of rain gauge network in the Middle Yarra River catchment, Australia DOI: 10.1002/hyp.10389.

[15] Keighobad Jafarzadegan, Venkatesh Merwade A DEM-based approach for large-scale floodplain mapping in ungauged watersheds. https://doi.org/10.1016/j.jhydrol.2017.04.053.

[16] Central Water Commission."Flood Forecasting/ Hydrological Observation"http://cwc.gov.in/flood-forecasting-hydrological.

[17] E. B. Panganiban and J. C. Dela Cruz, "Rain water level information with flood warning system using flat clustering predictive technique," TENCON 2017 - 2017 IEEE Region 10 Conference, Penang, 2017, pp. 727-732, doi: 10.1109/TENCON.2017.8227956. 